\title{
Molecular design and performance prediction of poly-dinitroamino pyrrole compounds as energetic materials
}

\author{
MEI LI, FENG-MIN WU and HANG XU* \\ Chemical Engineering and Pharmaceutics School, Henan University of Science and Technology, \\ Luoyang 471003, People's Republic of China \\ Email: xuhang_uhst@163.com
}

MS received 3 August 2016; revised 25 October 2016; accepted 26 October 2016

\begin{abstract}
To identify superior and safe energetic materials, eighteen poly-dinitroamino pyrrole derivatives were studied at the B3LYP/6-311G** level of density functional theory (DFT). The isodesmic reactions were employed to calculate the heats of formation $(H O F \mathrm{~s})$ for these compounds. The detonation velocity $(D)$ and pressure $(P)$ were evaluated using the Kamlet-Jacobs equations. Results indicate that $-\mathrm{N}\left(\mathrm{NO}_{2}\right)_{2}$ group is an effective substituent for enhancing the detonation performance since most of the molecules have larger energy density than RDX (1,3,5-trinitro-1,3,5-triazinane), and a few molecules, C1(N-R) - D3(N-R), with $D$ ranging from 8.55 to $9.04 \mathrm{~km} \mathrm{~s}^{-1}$ and $P$ ranging from 35.53 to $40.36 \mathrm{GPa}$ outperform $\mathrm{RDX}(D=$ $8.75 \mathrm{~km} \mathrm{~s}^{-1}$ and $\left.P=34.00 \mathrm{GPa}\right)$. The calculated bond dissociation energy $(B D E)$ revealed that the new compounds exhibit good thermal stability and meet the requirements of energetic materials. Besides, the $\mathrm{N}-\mathrm{NO}_{2}$ bond on the side chain was found to be the trigger bond during decomposition. The characteristic height $\left(h_{50}\right)$ of the compound was calculated, and thirteen compounds exhibited lower sensitivity than CL-20 (2,4,6,8,10,12-hexanitro-2,4,6,8,10,12-hexaazaisowurtzitane).
\end{abstract}

Keywords. High energy density materials; pyrrole derivatives; bond dissociation energy.

\section{Introduction}

Energetic materials for explosives, propellants and pyrotechnics are widely used in military and civilian fields. Searching for energetic materials with higher energy density and lower sensitivity is a joint goal of scientists engaged in designing and synthesizing materials. ${ }^{1-10}$ Among the various categories of energetic materials, five or six-membered nitrogen-containing heterocyclic compounds are regarded as promising candidates for high energy density materials (HEDMs) due to their desirable properties including high density, high positive heats of formation (HOFs) and high thermal stability. ${ }^{11}$ The presence of ring strain and abundantly energetic $\mathrm{C}-\mathrm{C}$ and $\mathrm{C}(\mathrm{N})-\mathrm{N}$ bonds contribute greatly to their high positive $\mathrm{HOF}$, and as a consequence, most of these compounds exhibit superior detonation behavior. For instance, HMX (1,3,5,7tetranitro-1,3,5,7-tetrazocane) and RDX (1,3,5-trinitro1,3,5-triazinane) are typical explosives in this class, both are characterized to have excellent detonation performance and good sensitivity, and find extensive applications in high explosive propellant formulations and pyrotechnic ingredients. ${ }^{12}$ TNTA (2,4,6-trinitro-1,3,5triazine) was proposed by Korkhin and Bartlett ${ }^{13}$ and

\footnotetext{
*For correspondence
}

their results demonstrate that TNTA is a new high performance energetic compound. ${ }^{13}$ However, the synthesis of such high energetic compound as HMX is still expensive and includes multiple steps in industrial production. Hence, intensive research is still required to develop novel energetic materials with large energy content and sufficient sensitivity.

The introduction of energy-rich functional groups including $-\mathrm{NO}_{2},-\mathrm{NNO}_{2},-\mathrm{ONO}_{2},-\mathrm{N}_{3},-\mathrm{N}=\mathrm{N}-$, and $-\mathrm{NF}_{2}$ as substituents in energetic compounds has been proved to be a straightforward and effective way for the enhancement of detonation performance (detonation velocity, pressure, etc.). ${ }^{14}$ Previous studies have shown that positive oxygen balance is requested for a compound to be a high performance energetic material. ${ }^{15,16}$ That is to say, sufficient oxygen atoms in a molecule should be incorporated when designing new energetic compounds. Therefore, the main concern in the present work is focused on the dinitroamino group $\left[\mathrm{N}\left(\mathrm{NO}_{2}\right)_{2}\right]$, which has the advantage of both high nitrogen and oxygen content. ${ }^{17}$ Besides, the nitrogen content of dinitroamino group is also higher than that of nitro, nitroso and nitramine groups. For example, Qiang Cao has designed twelve dinitroamino benzene derivatives, among which the molecule $\mathrm{C} 1(\mathrm{~N}-\mathrm{R})$ exhibits excellent detonation performance (detonation 
velocity is $10.0 \mathrm{~km} \mathrm{~s}^{-1}$ and detonation pressure is 45.5 GPa) with acceptable impact sensitivity. ${ }^{18}$ Although the chemistry and applications of pyrrole derivatives have been researched in detail in previous studies, the combination of pyrrole molecule with dinitroamino substituents has not been investigated. Hence, we designed eighteen poly-dinitroamino pyrrole derivatives by substituting the hydrogen atoms in pyrrole molecule with dinitroamino groups. Detonation velocity $(D)$ and pressure $(P)$ of the designed compounds were assessed using Kamlet-Jacobs equations. Calculations of bond dissociation energy and characteristic height were performed to evaluate whether the compounds are thermally stable and insensitive. We hope that the present work can be conducive to further experiments and the development of novel HEDMs.

\section{Computational methods}

The object molecules [A1(N-R)-A3, B1(N-R)-B6, C1(N$\mathrm{R})-\mathrm{C} 5, \mathrm{D} 1(\mathrm{~N}-\mathrm{R})-\mathrm{D} 3(\mathrm{~N}-\mathrm{R})$, and $\mathrm{E} 1(\mathrm{~N}-\mathrm{R})]$ are classed into five groups as shown in Figure 1. The geometries of all the molecules were optimized using the hybrid DFT-B3LYP method with the $6-311 \mathrm{G}^{* *}$ basis set and the optimized structures were confirmed to be local minima without imaginary frequencies. Harmonic vibrational frequencies and thermochemical parameters were obtained at the same level. Previous study has shown that the B3LYP/6-311G(d,p) is able to figure out the accurate energy, molecular structure, and<smiles>[R]n1cccc1</smiles>

Al(N-R)<smiles>[R]c1ccn(C)c1</smiles>

$\mathrm{B} 2(\mathrm{~N}-\mathrm{R})$<smiles>[R]c1c[nH]cc1[R]</smiles>

B6<smiles>[R]c1c[nH]c([R])c1[R]</smiles>

$\mathrm{C} 4$<smiles>[R]c1cc([R])n([R])c1[R]</smiles>

D3(N-R)<smiles>[R]c1ccc[nH]1</smiles>

A2<smiles>[R]c1cc[nH]c1[2H]</smiles>

B3<smiles>[R]c1ccn([R])c1[R]</smiles>

$\mathrm{Cl}(\mathrm{N}-\mathrm{R})$<smiles>[R]c1cc([R])c([R])[nH]1</smiles>

C5<smiles>[R]c1c([R])c([R])n([R])c1[R]</smiles>

E1(N-R)<smiles>[R]c1cc[nH]c1</smiles>

A3<smiles>[R]c1c[nH]c([R])c1</smiles>

B4<smiles>[R]c1cc([R])n([R])c1</smiles>

C2(N-R)<smiles>[R]c1cn([R])c([R])c1[R]</smiles>

Dl(N-R)<smiles>[R]c1cccn1C</smiles>

$\mathrm{B} 1(\mathrm{~N}-\mathrm{R})$<smiles>[R]c1ccc([R])[nH]1</smiles>

B5<smiles>[R]c1ccc([R])n1[R]</smiles>

C3(N-R)<smiles>[R]c1[nH]c([R])c([R])c1[R]</smiles>

D2

Figure 1. Molecular frameworks and names of pyrrole derivatives; $\mathrm{R}=$ $-\mathrm{N}\left(\mathrm{NO}_{2}\right)_{2}$. The molecules including $\mathrm{N}-\mathrm{N}\left(\mathrm{NO}_{2}\right)_{2}$ are labeled by $\mathrm{N}-\mathrm{R}$ in bracket. 
vibrational frequency that are very close to their experimental results. ${ }^{19}$ All calculations were performed with the Gaussian 09 package. ${ }^{20}$

$H O F$ is a key parameter for energetic compound, which is usually regarded as an indicator of energy content. The isodesmic reaction has been proven to be capable of providing reliable results of $\mathrm{HOF}$ in gas state for many organic systems. ${ }^{21-23}$ Hence, it was adopted here to evaluate the $H O F \mathrm{~s}$ of the designed molecules. The HOF of the isodesmic reaction at $298 \mathrm{~K}$ in gas phase $\left(\Delta H_{298}\right)$ can be calculated from the following equation:

$$
\begin{gathered}
\mathrm{C}_{4} \mathrm{H}_{4} \mathrm{~N}\left[\mathrm{~N}\left(\mathrm{NO}_{2}\right)_{2}\right]_{\mathrm{n}}+\mathrm{nCH}_{4} \rightarrow \mathrm{C}_{4} \mathrm{H}_{5} \mathrm{~N}+\mathrm{nCH}_{3} \mathrm{~N}\left(\mathrm{NO}_{2}\right)_{2} \\
\Delta H_{298}=\sum \Delta H_{\mathrm{f}, \mathrm{P}}-\sum \Delta H_{\mathrm{f}, \mathrm{R}}
\end{gathered}
$$

In Eq. (1), $\Delta H_{\mathrm{f}, \mathrm{P}}$ and $\Delta H_{\mathrm{f}, \mathrm{R}}$ are the HOFs of the products and reactants at $298 \mathrm{~K}$, respectively. The experimental HOFs of reference compounds are available from NIST Chemistry Book Website, the $\mathrm{HOF}$ values of $\mathrm{CH}_{4}, \mathrm{C}_{4} \mathrm{H}_{5} \mathrm{~N}$, and $\mathrm{CH}_{3} \mathrm{~N}\left(\mathrm{NO}_{2}\right)_{2}$ are $-74.4,143.2$, and $43.1 \mathrm{~kJ} / \mathrm{mol}$, respectively. ${ }^{24}$ Then the $H O F$ s of all targeted molecules can be calculated when $\Delta H_{298}$ is known. Therefore, the main quantity to compute is $\Delta H_{298}$, which can be evaluated using the following expression:

$$
\begin{aligned}
\Delta H_{298 \mathrm{~K}}= & \Delta E_{298 \mathrm{~K}}+\Delta(P V)=\Delta E_{0}+\Delta Z P E+\Delta H_{\mathrm{T}} \\
& +\Delta n R T
\end{aligned}
$$

where $\Delta E_{0}$ is the difference between the products and reactants at $0 \mathrm{~K}$, which is calculated at B3LYP/6-311G** level. $\triangle Z P E$ is the change in zero point energies (ZPE) of products and reactants and $\Delta H_{\mathrm{T}}$ is the thermal correction from 0 to $298 \mathrm{~K} . Z P E$ and $H_{\mathrm{T}}$ values of the investigated molecules are obtained from frequency calculation by using Gaussian 09 software package. ${ }^{20} \Delta(P V)$ is equal to $\Delta n R T$ for the reactions of an ideal gas.

Since most energetic materials are in solid state, prediction of detonation performance is possible when the solid state $H O F\left(H O F_{\text {solid }}\right)$ is known. According to Hess's law of constant heat summation, the gas phase HOF $\left(H O F_{\text {gas }}\right)$ and heat of sublimation $\left(H O F_{\text {sub }}\right)$ can be used to calculate the $H O F_{\text {solid }}$ :

$$
H O F_{\text {solid }}=H O F_{\text {gas }}-H O F_{\text {sub }}
$$

The $H O F_{\text {sub }}$ can be estimated using the following empirical expression: ${ }^{45}$

$$
H O F_{\text {sub }}=a A^{2}+b\left(v \sigma_{\text {tot }}^{2}\right)^{1 / 2}+c
$$

where $A$ is the surface area of 0.001 electrons $/ \mathrm{bohr}^{3}$ isosurface of the electronic density of molecule, $v$ describes the degree of balance between positive potential and negative potential on isosurface, and $\sigma_{\text {tot }}^{2}$ is a measure of the variability of electrostatic potential on molecular surface. The descriptors $A, v$, and $\sigma_{\text {tot }}^{2}$ were calculated using the computational procedures described by Bulat et al. ${ }^{30}$ The coefficients $a, b$, and $c$ were determined as described in Rice et al. ${ }^{25}$

The detonation velocity $(D)$ and pressure $(P)$ were estimated by the empirical Kamlet-Jacobs (K-J), K-J equations which can give reliable $D$ and $P$ for $\mathrm{C}-\mathrm{H}-\mathrm{N}-\mathrm{O}$ compound with density above $1.0 \mathrm{~g} / \mathrm{cm}^{3}$, as follows: ${ }^{26}$

$$
\begin{gathered}
D=1.01\left(N \bar{M}^{1 / 2} Q^{1 / 2}\right)^{1 / 2}(1+1.30 \rho) \\
P=1.558 \rho^{2} N \bar{M}^{1 / 2} Q^{1 / 2}
\end{gathered}
$$

where, $N$ is the number of moles of gaseous detonation products per gram of explosive, $\bar{M}$ is the average molecular weight of gaseous product; $N$ and $\bar{M}$ are calculated according to Chi's report. ${ }^{27} Q$ represents the chemical heat of detonation defined as the difference between the heat of formation of the products and reactants of the most exothermic reactions. $Q$ is frequently taken to be indicative of the "energy content/gram" of high energy density materials, which is determined based on the most exothermic principle. ${ }^{28}$ That is, all the $\mathrm{N}$ atoms turn into $\mathrm{N}_{2}$, the $\mathrm{O}$ atoms react with the $\mathrm{H}$ atoms to give $\mathrm{H}_{2} \mathrm{O}$ at first, and then form $\mathrm{CO}_{2}$ with the $\mathrm{C}$ atom. If the number of $\mathrm{O}$ atoms is more than what is needed to oxidize $\mathrm{H}$ and $\mathrm{C}$ atoms, redundant $\mathrm{O}$ atoms will convert into $\mathrm{O}_{2}$. For the $\mathrm{C}_{\mathrm{a}} \mathrm{H}_{\mathrm{b}} \mathrm{O}_{\mathrm{c}} \mathrm{N}_{\mathrm{d}}$ explosives, the values of $N, \bar{M}$ and $Q$ are calculated using the following formulae ${ }^{27}$ ( $M$ is the molecular weight of molecule):

\begin{tabular}{lccc}
\hline Parameters & \multicolumn{4}{c}{ explosive components conditions } \\
& $\mathrm{c} \geq(2 \mathrm{a}+\mathrm{b}) / 2$ & $(2 \mathrm{a}+\mathrm{b}) / 2>\mathrm{c} \geq \mathrm{b} / 2$ & $\mathrm{~b} / 2>\mathrm{c}$ \\
$N$ & $(\mathrm{~b}+2 \mathrm{c}+2 \mathrm{~d}) / 4 M$ & $(\mathrm{~b}+2 \mathrm{c}+2 \mathrm{~d}) / 4 M$ & $(\mathrm{~b}+\mathrm{d}) / 2 M$ \\
$\bar{M}$ & $4 \mathrm{M} /(\mathrm{b}+2 \mathrm{c}+2 \mathrm{~d})$ & $(56 \mathrm{~d}+88 \mathrm{c}-8 \mathrm{~b}) /(\mathrm{b}+2 \mathrm{c}+2 \mathrm{~d})$ & $(2 \mathrm{~b}+28 \mathrm{~d}+32 \mathrm{c}) /(\mathrm{b}+\mathrm{d})$ \\
$Q^{* 10^{-3}}$ & $\left(28.9 \mathrm{~b}+94.05 \mathrm{a}+0.239 H O F_{\text {solid }}\right) / M$ & $\left(28.9 \mathrm{~b}+94.05(\mathrm{c} / 2-\mathrm{b} / 4)+0.239 H O F_{\text {solid }}\right) / M$ & $\left(57.8 \mathrm{c}+0.239 H O F_{\text {solid }}\right) / M$
\end{tabular}

$\rho$ is the density of the explosive, which can be calculated using the method proposed by Politzer and coworkers and is expressed as: ${ }^{29-32}$

$$
\rho=\alpha\left(M / V_{\mathrm{m}}\right)+\beta\left(\nu \sigma_{\mathrm{tot}}^{2}\right)+\gamma
$$

$$
\begin{aligned}
\sigma_{\mathrm{tot}}^{2}= & \sigma_{+}^{2}+\sigma_{-}^{2}=\frac{1}{m} \sum_{i=1}^{m}\left[V^{+}\left(r_{\mathrm{i}}\right)-\bar{V}_{\mathrm{s}}^{+}\right]^{2} \\
& +\frac{1}{n} \sum_{j=1}^{n}\left[V^{-}\left(r_{\mathrm{j}}\right)-\bar{V}_{\mathrm{s}}^{-}\right]^{2}
\end{aligned}
$$




$$
\begin{gathered}
v=\sigma_{+}^{2} \sigma_{-}^{2} /\left|\sigma_{\mathrm{tot}}^{2}\right|^{2} \\
V_{\mathrm{s}}^{+}=\frac{1}{m} \sum_{i=1}^{m} V^{+}\left(r_{\mathrm{i}}\right) \\
V_{\mathrm{s}}^{-}=\frac{1}{n} \sum_{j=1}^{n} V^{-}\left(r_{\mathrm{j}}\right)
\end{gathered}
$$

The strength of bonding, which could be evaluated by bond dissociation energy $(B D E)$, is fundamental to understanding the thermal stability and decomposition mechanism of the energetic compound. The energy required for bond homolysis at $298 \mathrm{~K}$ and 1 atm corresponds to the enthalpy of reaction $A-B \rightarrow A \bullet+B \bullet$, which is bond dissociation enthalpy of molecule A-B by definition. For many organic molecules, the terms ' $B D E$ ' and 'bond dissociation enthalpy' often appear interchangeably in the literature. Therefore, $B D E$ can be given in terms of Eq. (13):

$$
B D E(A-B)=E(A \bullet)+E(B \bullet)-E(A-B)
$$

The $B D E$ with $Z P E$ correction can be calculated by Eq. (13):

$$
B D E(A-B)_{Z P E}=B D E(A-B)+\triangle Z P E
$$

where, $\triangle Z P E$ is the difference between the zero-point energy $(Z P E)$ of the products and the reactants.

The impact sensitivities of the studied compounds were evaluated by characteristic height $\left(h_{50}\right)$ using the Eq. (15), suggested by Pospíšl et al: ${ }^{33}$

$$
h_{50}=\alpha_{2} \sigma_{+}^{2}+\beta_{2} v+\gamma_{2}
$$

where the values of coefficients $\alpha_{2}, \beta_{2}$, and $\gamma_{2}$ are taken from Pospíšil. ${ }^{33}$

\section{Results and Discussion}

\subsection{Heats of formation ( $\mathrm{HOF}$ )}

Since $H O F$ reflects the energy content of the energetic compound and high positive $H O F$ is favorable for a potential energetic material, it is of great importance to accurately predict the HOF. Previous studies indicated that the use of isodesmic reactions, in which some of the bonds and electron pairs are effectively 'swapped' during the reaction, leads to a low error in the calculated value of the HOF. Table 1 lists the calculated total energies $\left(E_{0}\right)$, zero-point energies $\left(E_{\mathrm{ZPE}}\right)$, thermal correction $\left(H_{\mathrm{T}}\right), H O F_{\text {sub }}, H O F_{\text {gas }}$, and $H O F_{\text {solid }}$ of the designed molecules at B3LYP/6-311G** level. Results show that the $H O F_{\text {solid }}$ of all the molecules in the range of 153 to $589 \mathrm{~kJ} \mathrm{~mol}^{-1}$ are higher than that of RDX $\left(79.00 \mathrm{~kJ} \mathrm{~mol}^{-1}\right)$, indicating that the designed molecules may exhibit better energetic properties than RDX.

It is clear from Table 1 that with the number of $-\mathrm{N}\left(\mathrm{NO}_{2}\right)_{2}$ group increasing, the $H O F_{\text {solid }}$ of the target molecules increase, which may be attributed to the repulsion of $-\mathrm{N}\left(\mathrm{NO}_{2}\right)_{2}$ groups. Additionally, it can be found that the compounds containing $\mathrm{N}-\mathrm{N}\left(\mathrm{NO}_{2}\right)_{2}$ unit have larger $H O F_{\text {solid }}$ for isomers. For example, the $H O F_{\text {solid }}$ of $\mathrm{A} 1(\mathrm{~N}-\mathrm{R})\left(257.40 \mathrm{~kJ} \mathrm{~mol}^{-1}\right)$ is larger than that of A2 $(153.90 \mathrm{~kJ} / \mathrm{mol})$ and A3 $\left(156.33 \mathrm{~kJ} \mathrm{~mol}^{-1}\right)$, demonstrating that the value of $H O F_{\text {solid }}$ relates to the nature of $\mathrm{C}-\mathrm{N}\left(\mathrm{NO}_{2}\right)_{2}$ and $\mathrm{N}-\mathrm{N}\left(\mathrm{NO}_{2}\right)_{2}$. Similar cases can be found in $\mathrm{B}, \mathrm{C}$, and $\mathrm{D}$ series. The results indicate that $\mathrm{N}-\mathrm{N}$ bond plays a more important role to increase

Table 1. Total energies ( $E_{0}$, a.u.), zero point energies ( $E_{\mathrm{ZPE}}$, a.u.), thermal correction values $\left(H_{\mathrm{T}}\right.$, a.u. $)$, heat of formation $(\mathrm{kJ} / \mathrm{mol})$ of the pyrrole derivatives at the B3LYP/6-311G** level.

\begin{tabular}{lcccccc}
\hline Compounds & $E_{0}$ & $E_{\text {ZPE }}$ & $H_{\mathrm{T}}$ & $\Delta H_{\text {sub }}$ & $H O F_{\text {gas }}$ & $H O F_{\text {solid }}$ \\
\hline A1(N-R) & -674.60151 & 0.10115 & -0.01132 & 23.93 & 281.33 & 257.40 \\
A2 & -674.64145 & 0.10234 & -0.01123 & 25.90 & 179.80 & 153.90 \\
A3 & -674.63963 & 0.10260 & -0.01123 & 28.95 & 185.28 & 156.33 \\
B1(N-R) & -1139.01010 & 0.12101 & -0.01781 & 35.45 & 360.47 & 325.02 \\
B2(N-R) & -1139.00914 & 0.12088 & -0.01800 & 39.26 & 362.16 & 322.90 \\
B3 & -1139.04714 & 0.12218 & -0.01790 & 36.75 & 266.06 & 229.31 \\
B4 & -1139.04939 & 0.12210 & -0.01790 & 37.96 & 259.96 & 222.01 \\
B5 & -1139.04811 & 0.12178 & -0.01795 & 36.38 & 262.32 & 225.94 \\
B6 & -1139.04774 & 0.12251 & -0.01778 & 37.60 & 265.66 & 228.06 \\
C1(N-R) & -1603.41114 & 0.14044 & -0.02474 & 50.92 & 457.16 & 406.23 \\
C2(N-R) & -1603.41360 & 0.14044 & -0.02463 & 50.58 & 451.00 & 400.42 \\
C3(N-R) & -1603.41158 & 0.14044 & -0.02466 & 48.35 & 456.23 & 407.88 \\
C4 & -1603.45098 & 0.14232 & -0.02421 & 47.56 & 358.91 & 311.35 \\
C5 & -1603.45008 & 0.14119 & -0.02478 & 51.67 & 356.83 & 305.15 \\
D1(N-R) & -2067.81106 & 0.16047 & -0.03117 & 65.59 & 559.69 & 494.10 \\
D2 & -2067.84996 & 0.16178 & -0.03088 & 62.66 & 461.74 & 399.09 \\
D3(N-R) & -2067.81091 & 0.16016 & -0.03116 & 62.90 & 559.30 & 496.40 \\
E1(N-R) & -2532.20790 & 0.17970 & -0.03785 & 78.30 & 667.54 & 589.24 \\
\hline
\end{tabular}


$H O F_{\text {solid }}$ of the energetic material than $\mathrm{C}-\mathrm{N}$ bond. On the whole, all the studied dinitroamino-substituted pyrrole derivatives have the potential of being excellent energetic compounds from the $H O F$ point of view.

\subsection{Detonation performance}

Detonation velocity $(D)$ and pressure $(P)$ are two important performance parameters for the energetic materials and they refer to the stable velocity of the shock front that characterizes detonation and the stable pressure that is developed behind the front, respectively. ${ }^{34}$ The predicted $\rho, D, P$, and heat of explosion $(Q)$ are given in Table 2. The calculated $\rho$ of the designed compounds lies in the range of 1.59 to $2.03 \mathrm{~g} \mathrm{~cm}^{-3}$, among which B1(N-R), B3, B6, and $\mathrm{C}, \mathrm{D}$, and $\mathrm{E}$ series possess higher values $\rho$ (1.83$\left.2.13 \mathrm{~g} \mathrm{~cm}^{-3}\right)$ than $\operatorname{RDX}\left(1.81 \mathrm{~g} \mathrm{~cm}^{-3}\right), .^{35}$ revealing that they are promising energetic molecules. It is obvious that $\rho$ of the studied molecules displays an overall increasing tendency as the number of dinitroamino groups increases, apart from the slight decrease for molecule E. This indicates that the dinitroamino substituent could enhance the densities of the resultant compounds positively. Inspecting $Q$ values given in Table 2, we find that the molecules with inclusion of $\mathrm{N}-\mathrm{N}\left(\mathrm{NO}_{2}\right)_{2}$ show larger $Q$ values than the ones with only $\mathrm{C}-\mathrm{N}\left(\mathrm{NO}_{2}\right)_{2}$, which suggests that introduction of $\mathrm{N}-\mathrm{N}$ bond into the molecular skeleton is an effective way for increasing $Q$ values. Although all pyrrole derivatives are unfortunately predicted to have smaller $Q$ values than RDX, the relatively large $\rho$ of them facilitate the resultant compounds to exhibit comparable or better detonation performance compared with RDX. To be specific, taking $\mathrm{C} 2(\mathrm{~N}-\mathrm{R})$ as the example, it possesses smaller $Q$ value $\left(1330.90 \mathrm{cal} \mathrm{g}^{-1}\right)$ but higher $\rho$ $\left(1.97 \mathrm{~g} \mathrm{~cm}^{-3}\right)$ than $\operatorname{RDX}\left(Q=1591.03 \mathrm{cal} \mathrm{g}^{-1}\right.$ and $\rho=1.82 \mathrm{~g} \mathrm{~cm}^{-3}$ ), and as a consequence, C2(N-R) displays better energetic properties $\left(D=9.04 \mathrm{~km} \mathrm{~s}^{-1}\right.$ and $P=40.36 \mathrm{GPa})$ than $\operatorname{RDX}\left(D=8.75 \mathrm{~km} \mathrm{~s}^{-1}\right.$ and $P=34.00 \mathrm{GPa}$ ). This demonstrates that $\rho$ may contribute more than $Q$ to the detonation behavior of energetic materials, which has been shown in the previous study. ${ }^{36}$ Moreover, it can be easily found that molecules of $\mathrm{C}$ series surpass RDX on detonation performance and molecules of $\mathrm{D}$ and $\mathrm{E}$ series all have comparable $D$ and $P$ values to RDX. Therefore, we recommend $\mathrm{C} 1(\mathrm{~N}-\mathrm{R})-\mathrm{C} 5$ as the most promising energetic compound, considering their excellent energetic properties.

\subsection{Molecular stability}

The highest occupied molecular orbitals (HOMOs) and the lowest unoccupied molecular orbitals (LUMOs) are designated as frontier molecular orbitals (FMOs). The energy gap ( $\left.\Delta E_{\text {LUMO-HOMO }}\right)$ between HOMO and LUMO determines the kinetic stability, chemical reactivity and optical polarizability and chemical hardnesssoftness of a molecule. ${ }^{38}$ Larger the energy gap is,

Table 2. Predicted detonation properties of the poly-dinitroaminopyrroles and RDX calculated at the B3LYP/6-311G** level.

\begin{tabular}{lcccccc}
\hline Compound & $N$ & $\bar{M}$ & $\rho\left(\mathrm{g} / \mathrm{cm}^{3}\right)$ & $Q(\mathrm{cal} / \mathrm{g})$ & $D(\mathrm{~km} / \mathrm{s})$ & $P(\mathrm{GPa})$ \\
\hline A1(N-R) & 0.0291 & 27.20 & 1.59 & 1035.57 & 6.85 & 19.28 \\
A2 & 0.0291 & 27.20 & 1.63 & 891.76 & 6.69 & 18.66 \\
A3 & 0.0291 & 27.20 & 1.70 & 895.13 & 6.90 & 20.40 \\
B1(N-R) & 0.0298 & 32.48 & 1.83 & 605.16 & 6.97 & 21.72 \\
B2(N-R) & 0.0298 & 32.48 & 1.79 & 603.33 & 6.87 & 20.92 \\
B3 & 0.0298 & 32.48 & 1.83 & 522.58 & 6.74 & 20.36 \\
B4 & 0.0298 & 32.48 & 1.80 & 516.28 & 6.62 & 19.41 \\
B5 & 0.0298 & 32.48 & 1.77 & 519.67 & 6.55 & 18.85 \\
B6 & 0.0298 & 32.48 & 1.84 & 521.50 & 6.75 & 20.52 \\
C1(N-R) & 0.0289 & 34.61 & 1.93 & 1334.40 & 8.98 & 39.15 \\
C2(N-R) & 0.0289 & 34.61 & 1.97 & 1330.90 & 9.04 & 40.36 \\
C3(N-R) & 0.0289 & 34.61 & 1.92 & 1335.39 & 8.79 & 39.56 \\
C4 & 0.0289 & 34.61 & 1.98 & 1277.42 & 8.90 & 37.09 \\
C5 & 0.0289 & 34.61 & 1.96 & 1273.70 & 8.82 & 38.23 \\
D1(N-R) & 0.0276 & 36.27 & 2.13 & 977.93 & 8.66 & 36.58 \\
D2 & 0.0276 & 36.27 & 2.12 & 935.48 & 8.55 & 35.53 \\
D3(N-R) & 0.0276 & 36.27 & 2.11 & 978.95 & 8.62 & 36.11 \\
E1(N-R) & 0.0296 & 33.78 & 2.03 & 850.38 & 8.24 & 32.31 \\
RDX & & & $1.78(1.82)$ & 1591.03 & $8.87(8.75)$ & $34.67(34.00)$ \\
\hline The val & & & & & &
\end{tabular}

The values in parentheses denote experimental values of RDX. ${ }^{37}$ 
better is the stability of the material. Table 3 lists the energies of HOMO ( $\left.E_{\text {Номо }}\right)$ and LUMO $\left(E_{\mathrm{LUMO}}\right)$, and $\Delta E_{\mathrm{LUMO}-\mathrm{HOmo}}$ of the designed molecules, pyrrole and TATB (triaminotrinitrobenzene) at B3LYP/6-311G** level.

On the whole, the order of stability is $\mathrm{E} 1(\mathrm{~N}-\mathrm{R})>\mathrm{B} 6>$ $\mathrm{C} 4>\mathrm{D} 3(\mathrm{~N}-\mathrm{R})>\mathrm{C} 3(\mathrm{~N}-\mathrm{R})>\mathrm{D} 2>\mathrm{C} 2(\mathrm{~N}-\mathrm{R})>\mathrm{D} 1(\mathrm{~N}-$ R) $>\mathrm{C} 5>\mathrm{C} 1(\mathrm{~N}-\mathrm{R})>\mathrm{B} 3>\mathrm{B} 4>\mathrm{B} 5>\mathrm{A} 3>$ $\mathrm{B} 1(\mathrm{~N}-\mathrm{R})>\mathrm{B} 2(\mathrm{~N}-\mathrm{R})>\mathrm{A} 2>\mathrm{A} 1(\mathrm{~N}-\mathrm{R})$. The stability of the dinitroamino substituted pyrrole derivatives shows an increasing tendency as the number of the substituents increases. This indicates that the dinitroamino groups may have a positive effect on the stability of the resultant compounds. Moreover, we find that the compounds of the same series with $\mathrm{N}-\mathrm{N}\left(\mathrm{NO}_{2}\right)_{2}$ unit display lower $\Delta E_{\text {LUMO-HOMO }}$ than the other ones; for example, B1(N-R) and $\mathrm{B} 2(\mathrm{~N}-\mathrm{R})$ show lower $\Delta E_{\mathrm{LUMO}-\text { номо }}$ than $\mathrm{B} 3-\mathrm{B} 6$. Besides, compounds apart from $\mathrm{A} 1(\mathrm{~N}-\mathrm{R})-\mathrm{A} 3, \mathrm{~B} 1(\mathrm{~N}-\mathrm{R}), \mathrm{B} 2(\mathrm{~N}-\mathrm{R}), \mathrm{B} 4$ and $\mathrm{B} 5$, all display better stability behavior with $\Delta E_{\mathrm{LUMO}-\mathrm{HOMO}}$ ranging from 0.16264 to 0.17343 a.u. than the extensively used explosive TATB $\left(\Delta E_{\text {LUMO-Hомо }}=0.16210\right.$ a.u.), which is an insensitive high explosive. Therefore, most of the designed molecules can be anticipated to show excellent stability. However, the $\Delta E_{\text {LUMO-HOMO }}$ values of all the derivatives are smaller that of TNT. It should be pointed out that the stability discussed in this

Table 3. Calculated HOMO ( $E_{\text {HOMO }}$, a.u.) and LUMO ( $E_{\mathrm{LOMO}}$, a.u.) energies as well as the energy gaps ( $\Delta E_{\text {LUMO-Homo, }}$ a.u.) of the title compounds at the B3LYP/6-311G** level.

\begin{tabular}{lrrr}
\hline Compound & $E_{\text {LUMO }}$ & $E_{\text {HOMO }}$ & $\Delta E_{\text {LUMO-HOMO }}$ \\
\hline $\mathrm{C}_{4} \mathrm{H}_{5} \mathrm{~N}$ & 0.03656 & -0.21237 & 0.24893 \\
$\mathrm{~A} 1(\mathrm{~N}-\mathrm{R})$ & -0.11018 & -0.24992 & 0.13974 \\
$\mathrm{~A} 2$ & -0.10732 & -0.25403 & 0.14671 \\
$\mathrm{~A} 3$ & -0.09608 & -0.25126 & 0.15518 \\
$\mathrm{~B} 1(\mathrm{~N}-\mathrm{R})$ & -0.12013 & -0.27503 & 0.15490 \\
$\mathrm{~B} 2(\mathrm{~N}-\mathrm{R})$ & -0.12717 & -0.27974 & 0.15257 \\
$\mathrm{~B} 3$ & -0.11383 & -0.27647 & 0.16264 \\
$\mathrm{~B} 4$ & -0.12447 & -0.28324 & 0.15877 \\
$\mathrm{~B} 5$ & -0.12485 & -0.28028 & 0.15543 \\
$\mathrm{~B} 6$ & -0.10645 & -0.27844 & 0.17199 \\
$\mathrm{C} 1(\mathrm{~N}-\mathrm{R})$ & -0.13384 & -0.29705 & 0.16321 \\
$\mathrm{C} 2(\mathrm{~N}-\mathrm{R})$ & -0.13322 & -0.29819 & 0.16497 \\
$\mathrm{C} 3(\mathrm{~N}-\mathrm{R})$ & -0.12850 & -0.29372 & 0.16522 \\
$\mathrm{C} 4$ & -0.12357 & -0.29268 & 0.16911 \\
$\mathrm{C} 5$ & -0.13267 & -0.29636 & 0.16369 \\
D1(N-R) & -0.14119 & -0.30574 & 0.16455 \\
D2 & -0.13557 & -0.30077 & 0.16520 \\
D3(N-R) & -0.13873 & -0.30442 & 0.16569 \\
E1(N-R) & -0.14417 & -0.31760 & 0.17343 \\
TATB & -0.10280 & -0.26480 & 0.16210 \\
TNT & -0.1341 & -0.31784 & 0.18374 \\
\hline
\end{tabular}

part refers to the stability in chemical or photochemical processes with electron transfer or leap.

The bond dissociation energy $(B D E)$ of the trigger bond is often a key factor in investigating the thermal stability and pyrolysis mechanism for energetic compounds. ${ }^{39,40}$ Generally, the smaller the energy needed for breaking a bond, the weaker is the bond. To elucidate the pyrolysis mechanism and thermal stability of all molecules, two possible types of bond dissociation have been considered in the present work: (1) the Ring-N bonds in the ring; (1) the $\mathrm{N}-\mathrm{NO}_{2}$ bond on the side chain. It should be pointed out that among the same kind of bonds, the weakest bond is selected as the breaking bond according to the results of Wiberg bond index (WBI). The WBI and $B D E$ values of Ring$\mathrm{N}$ and $\mathrm{N}-\mathrm{NO}_{2}$ bonds $\left(P_{\text {Ring-N }}, P_{\mathrm{N}-\mathrm{NO} 2}, B D E_{\text {Ring-N }}\right.$, and $B D E_{\mathrm{N}-\mathrm{NO} 2}$, respectively) are presented in Table 4.

As observed, both $P_{\text {Ring-N }}$ and $B D E_{\text {Ring-N }}$ of Ring-N bonds are much larger than those of $\mathrm{N}-\mathrm{NO}_{2}$ bonds, that is to say, $\mathrm{N}-\mathrm{NO}_{2}$ bonds are weaker than Ring- $\mathrm{N}$ bonds and may be the trigger bonds during decomposition progress. In addition, we find that molecules of $\mathrm{A}, \mathrm{B}$, and $\mathrm{C}$ series which contain $\mathrm{N}-\mathrm{N}\left(\mathrm{NO}_{2}\right)_{2}$ fragment have smaller $B D E$ than that of other isomers. This may be attributed to the different electron-withdrawing effect between $\mathrm{C}$ and $\mathrm{N}$ atoms. On the whole, although all the designed compounds have smaller $B D E$ values than RDX and TNT, they have met the stability requirement suggested previously, that is, a molecule could be considered as a practical energetic material if it has $B D E$ more than $84 \mathrm{~kJ} \mathrm{~mol}^{-1}$. 41

The impact sensitivity is one of the crucial parameters responsible for effectiveness and it reflects whether the explosive is stable enough to handle or store. ${ }^{42,43} \mathrm{In}$ this work, the estimation of sensitivity is assessed based on the characteristic height $\left(h_{50}\right)$, which is defined as the height from which a given weight of $2.5 \mathrm{~kg}$ falling upon a compound has a 50\% probability of producing an explosion. Table 5 lists the calculated $h_{50}$ values by Pospísil method ${ }^{33}$ for each compound together with the experimental value of CL-20 for comparison. It is clear that except for $\mathrm{C} 4, \mathrm{C} 5, \mathrm{D} 2, \mathrm{D} 3(\mathrm{~N}-\mathrm{R})$ and $\mathrm{E} 1(\mathrm{~N}-$ $\mathrm{R})$, other compounds all display lower sensitivity than CL-20 $\left(h_{50}=12 \mathrm{~cm}\right)$.

An apparent trend is that the $h_{50}$ value decreases as the number of substituent group increases, indicating that the dinotroamino group has negative effects on sensitivity. As for isomers, compounds of the same series with $\mathrm{N}-\mathrm{N}\left(\mathrm{NO}_{2}\right)_{2}$ unit display lower sensitivity than other ones; for example, $h_{50}$ values for B1(N-R) and $\mathrm{B} 2(\mathrm{~N}-\mathrm{R})$ are 29 and $31 \mathrm{~cm}$, while this value ranges from 15 to $17 \mathrm{~cm}$ for molecules B3-B6. This indicates that N-N bond is better for improving $h_{50}$ of energetic material 
Table 4. Calculated Wiberg bond index (WBI) of part bonds and bond dissociation energies $\left(\mathrm{kJ} \mathrm{mol}^{-1}\right)$ of the trigger bonds at the UB3LYP/6-311G** level.

\begin{tabular}{lcccc}
\hline Compound & $P_{\text {Ring-N(NO2)2 }}$ & $B D E_{\mathrm{ZPE}(\mathrm{Ring}-\mathrm{N}(\mathrm{NO} 2) 2)}$ & $P_{\mathrm{N}-\mathrm{NO} 2}$ & $B D E_{\mathrm{ZPE}(\mathrm{N}-\mathrm{NO} 2)}$ \\
\hline $\mathrm{A} 1(\mathrm{~N}-\mathrm{R})$ & 1.1115 & 325.71 & 0.7137 & 92.07 \\
$\mathrm{~A} 2$ & 1.0533 & 424.42 & 0.7681 & 108.31 \\
A3 & 1.0192 & 418.89 & 0.7631 & 109.48 \\
$\mathrm{~B} 1(\mathrm{~N}-\mathrm{R})$ & 1.0701 & 422.92 & 0.6930 & 89.39 \\
B2(N-R) & 1.0092 & 41.55 & 0.7198 & 97.68 \\
B3 & 1.0184 & 405.24 & 0.7555 & 108.07 \\
B4 & 1.0144 & 415.77 & 0.7713 & 116.54 \\
B5 & 1.0295 & 415.58 & 0.7723 & 102.23 \\
B6 & 1.0172 & 423.13 & 0.7345 & 106.06 \\
C1(N-R) & 1.0168 & 393.14 & 0.6808 & 98.67 \\
C2(N-R) & 1.0131 & 404.23 & 0.6993 & 98.31 \\
C3(N-R) & 1.0551 & 422.67 & 0.7013 & 97.12 \\
C4 & 1.0155 & 419.26 & 0.7712 & 116.22 \\
C5 & 1.0147 & 409.05 & 0.7298 & 105.72 \\
D1(N-R) & 1.0169 & 414.10 & 0.7004 & 103.93 \\
D2 & 1.0186 & 418.45 & 0.7330 & 104.52 \\
D3(N-R) & 1.0162 & 408.53 & 0.7045 & 102.07 \\
E1(N-R) & 1.0185 & 410.33 & 0.7113 & 115.26 \\
RDX & $/$ & $/$ & $/$ & 160.41 \\
TNT & & & & $242.44\left(\mathrm{C}-\mathrm{NO}_{2}\right)$ \\
\hline
\end{tabular}

Table 5. Calculated characteristic height $\left(h_{50}, \mathrm{~cm}\right)$ of the designed compounds and experimental characteristic height of CL-20.

\begin{tabular}{lrcr}
\hline Compounds & $\sigma_{+}^{2}$ & $v$ & $h_{50}$ \\
\hline A1(N-R) & 58.73 & 0.1740 & 38.20 \\
A2 & 126.64 & 0.1563 & 33.49 \\
A3 & 196.76 & 0.1562 & 33.03 \\
B1(N-R) & 97.20 & 0.1361 & 28.79 \\
B2(N-R) & 122.05 & 0.1463 & 31.11 \\
B3 & 225.06 & 0.0919 & 17.32 \\
B4 & 193.10 & 0.0903 & 17.12 \\
B5 & 140.57 & 0.0821 & 15.48 \\
B6 & 294.68 & 0.0848 & 15.15 \\
C1(N-R) & 140.86 & 0.0851 & 16.20 \\
C2(N-R) & 142.43 & 0.0740 & 13.53 \\
C3(N-R) & 130.79 & 0.0657 & 11.60 \\
C4 & 264.71 & 0.0644 & 10.43 \\
C5 & 208.08 & 0.0588 & 9.44 \\
D1(N-R) & 150.49 & 0.0741 & 13.51 \\
D2 & 212.89 & 0.0531 & 8.03 \\
D3(N-R) & 121.43 & 0.0576 & 9.69 \\
E1(N-R) & 112.06 & 0.0503 & 8.01 \\
CL-20 & $/$ & $/$ & 12 \\
\hline
\end{tabular}

compared with C-N bond. However, it is found that the conclusion drawn based on $h_{50}$ is not very consistent with that from BDE. For instance, B4 has the largest BDE value while A1(N-R) shows the most insensitive property. This supports the viewpoint of Politzer that there is no general correlation between bond strength and impact sensitivity; any such correlation is limited to a certain class of molecules. ${ }^{44}$

\section{Conclusions}

In the present work, we studied the heats of formation, electronic structures, energetic properties and thermal stabilities of eighteen poly-dinitroamino pyrrole derivatives using the DFT-B3LYP method. The gas and solid phase $H O F$ of the designed compounds were calculated by designing appropriate isodesmic reactions and all the target compounds were predicted to possess larger $H O F_{\text {solid }}$ than RDX, indicating that all compounds may have large energy content. The $D$ and $P$ results show that the detonation performance of molecules of $\mathrm{C}, \mathrm{D}$ and $\mathrm{E}$ series are comparable to or even better than that of RDX, revealing that the introduction of $-\mathrm{N}\left(\mathrm{NO}_{2}\right)_{2}$ group into pyrrole molecule is beneficial to the enhancement of energetic property of the resultant compounds. The molecular stabilities and impact sensitivities were estimated through $B D E$ and $h_{50}$, respectively. $B D E$ s of trigger bonds for all the molecules are large enough to suffice the stability requirement of explosives, and most of the designed molecules have larger $h_{50}$ than CL-20. Thus, all the compounds display good thermal stability and most of them possess acceptable sensitivity. On the whole, $\mathrm{C} 1(\mathrm{~N}-\mathrm{R}), \mathrm{C} 2(\mathrm{~N}-$ $\mathrm{R}), \mathrm{C} 3(\mathrm{~N}-\mathrm{R})$, and $\mathrm{D} 1(\mathrm{~N}-\mathrm{R})$ may be the most promising energetic compounds due to their superior energetic 
properties compared to RDX and lower sensitivity than CL-20.

\section{Acknowledgements}

This work was supported by the National Nature Science Foundation of China (No. 21006057).

\section{References}

1. Zhang J and Shreeve J M 2014 3, 3-Dinitroamino-4,4azoxyfurazan and its derivatives: An assembly of diverse $\mathrm{N}-\mathrm{O}$ building blocks for high-performance energetic materials J. Am. Chem. Soc. 1364437

2. Chi W-J and Li Z-S 2015 Molecular design of prismanebased potential energetic materials with high detonation performance and low impact sensitivity C.R. Chim. 18 1270

3. Zhang X, Liu Y, Wang F and Gong X 2014 A theoretical study on the structure, intramolecular interactions, and detonation performance of hydrazinium dinitramide Chem-Asian J. 9229

4. Wu Q, Zhu W and Xiao H 2014 Thermal decomposition of solid phase nitromethane under various heating rates and target temperatures based on ab initio molecular dynamics simulations J. Mol. Model 202438

5. Li X H, Cui H L, Li L B and Zhang X Z 2013 Theoretical investigation on crystal structure, detonation performance and thermal stability of a high density cage hexanitrohexaazaisowurtzitane derivative J. Chem. Sci. 125919

6. Vaitheeswaran G and Babu K R 2012 Metal azides under pressure: An emerging class of high energy density materials J. Chem. Sci. 1241391

7. Li X H and Zhang R Z 2014 Computational studies on energetic properties of nitrogen-rich energetic materials with ditetrazoles J. Chem. Sci. 1261753

8. Guo D, Zybin S V, An Q, Goddard III W A and Huang F 2016 Prediction of the Chapman-Jouguet chemical equilibrium state in a detonation wave from first principles based reactive molecular dynamics Phys. Chem. Chem. Phys. 182015

9. Xiang $\mathrm{D}, \mathrm{Wu} \mathrm{Q}, \mathrm{LIU} \mathrm{Z}, \mathrm{Zhu} \mathrm{W}$ and Xiao $\mathrm{H}$ 2015 Pressure-induced changes in the structural and absorption properties of crystalline 5-nitramino-3,4dinitropyrazole J. Chem. Sci. 1271777

10. Bera A and Bhattacharya A 2015 Excited electronic state decomposition mechanisms of clusters of dimethylnitramine and aluminum J. Chem. Sci. 12771

11. Jaidann M, Roy S, Abou-Rachid H and Lussier L-S 2010 A DFT theoretical study of heats of formation and detonation properties of nitrogen-rich explosives J. Hazard. Mater 176165

12. Zhang Q, Zhang J, Qi X and Shreeve J M 2014 Molecular design and property prediction of high density polynitro[3.3.3]-propellane-derivatized frameworks as potential high explosives J. Phys. Chem. A 11810857

13. Korkin A A and Bartlett R J 1996 Theoretical prediction of 2, 4, 6-trinitro-1, 3, 5-triazine (TNTA). A new, powerful, high-energy density material? J. Am. Chem. Soc. 11812244
14. Gao H and Jean'ne M S 2014 Trinitroethyl-a functionality leading to energetic compounds with high nitro content RSC Adv. 424874

15. Huang H, Shi Y, Liu Y and Yang J 2016 Chem-Asian J. 111688

16. Zhao X, Li S, Wang Y, Li Y, Zhao F and Pang S 2016 J. Mater. Chem. A 45495

17. Chi W and Li Z 2015 Theoretical prediction of detonation performance and stability for energetic polydinitroaminoprismanes RSC Adv. $\mathbf{5 7 7 6 6}$

18. Cao Q 2013 Dinitroamino benzene derivatives: A class new potential high energy density compounds $\mathrm{J}$. Mol. Model 192205

19. Wang F, Wang G, Du H, Zhang J and Gong X 2011 Theoretical studies on the heats of formation, detonation properties, and pyrolysis mechanisms of energetic cyclic nitramines J. Phys. Chem. A 11513858

20. Frisch M J, Trucks G W, Schlegel H B, Scuseria G E, Robb M A, Cheeseman J R, Montgomery J A, Vreven T, Kudin K N, Burant J C, Millam J M, Iyengar S S, Tomasi J, Barone V, Mennucci B, Cossi M, Scalmani G, Rega N, Petersson G A, Nakatsuji H, Hada M, Ehara M, Toyota K, Fukuda R, Hasegawa J, Ishida M, Nakajima T, Honda Y, Kitao O, Nakai H, Klene M, Li X, Knox J E, Hratchian H P, Cross J B, Adamo C, Jaramillo J, Gomperts R, Stratmann R E, Yazyev O, Austin A J, Cammi R, Pomelli C, Ochterski J W, Ayala P Y, Morokuma K, Voth G A, Salvador P, Dannenberg J J, Zakrzewski V G, Dapprich S, Daniels A D, Strain M C, Farkas O, Malick D K, Rabuck A D, Raghavachari K, Foresman J B, Ortiz J V, Cui Q, Baboul A G, Clifford S, Cioslowski J, Stefanov B B, Liu G, Liashenko A, Piskorz P, Komaromi I, Martin R L, Fox D J, Keith T, AlLaham M A, Peng C Y, Nanayakkara A, Challacombe M, Gill P M W, Johnson B, Chen W, Wong M W, Gonzalez C and Pople J A, Gaussian 09 (Wallingford CT, Gaussian Inc.) (2009)

21. Wang F, Du H, Zhang J and Gong X 2011 Computational studies on the crystal structure, thermodynamic properties, detonation performance, and pyrolysis mechanism of 2, 4, 6, 8-tetranitro-1, 3, 5, 7-tetraazacubane as a novel high energy density material J. Phys. Chem. A 11511788

22. Singh R, Singh H J and Sengupta S 2015 Computational studies on 1,2, 4-Triazolium-based salts as energetic materials J. Chem. Sci. 1271099

23. Zhang R Z, Li X H and Zhang X Z 2012 Theoretical studies on a series of 1,2,4-triazoles derivatives as potential high energy density compounds J. Chem. Sci. 124995

24. National Institute of Standards and Technology (NIST). "NIST Chemistry WebBook." http://webbook.nist.gov/ chemistry/ (Accessed on 9 February 2015)

25. Rice B M, Pai S V and Hare J 1999 Predicting heats of formation of energetic materials using quantum mechanical calculations Combust. Flame 118445

26. Kamlet M J and Jacobs S J 1968 The Chemistry of Detonations. 1. A Simple method for Calculating Detonation Properties of CHNO Explosives J. Chem. Phys. 4823

27. Chi W-J, Li L-L, Li B-T and Wu H-S 2012 Density functional study on the derivatives of purine J. Mol. Model 183501 
28. Yu Z and Bernstein E R 2013 Sensitivity and performance of azole-based energetic materials J. Phys. Chem. A 11710889

29. Politzer P, Martinez J, Murray J S, Concha M C and Toro-Labbe A 2009 An electrostatic interaction correction for improved crystal density prediction Mol. Phys. 1072095

30. Bulat F A, Toro-Labbé A, Brinck T, Murray J S and Politzer P 2010 Quantitative analysis of molecular surfaces: Areas, volumes, electrostatic potentials and average local ionization energies J. Mol. Model 161679

31. Politzer P, Murray J S and Bulat F A 2010 Average local ionization energy: A review J. Mol. Model 161731

32. Bulat F A, Toro-Labbé A, Champagne B, Kirtman B and Yang W 2005 Density-functional theory (hyper) polarizabilities of push-pull $\pi$-conjugated systems: Treatment of exact exchange and role of correlation J. Chem. Phys. 123014319

33. Pospíśil M, Vávra P, Concha M C, Murray J S and Politzer P 2010 A possible crystal volume factor in the impact sensitivities of some energetic compounds J. Mol. Model 16895

34. Ma Q, Jiang T, Zhang X, Fan G, Wang J and Huang J 2015 Theoretical investigations on $4,4^{\prime}, 5,5^{\prime}$ tetranitro2, $2^{\prime} 1 \mathrm{H}, 1^{\prime} \mathrm{H} 2,2^{\prime}$ biimidazole derivatives as potential nitrogenrich high energy materials J. Phys. Org. Chem. 2831

35. Storm C, Stine J and Kramer J 1990 In Chemistry and Physics of Energetic Materials (Berlin: Springer) p. 605

36. Politzer P and Murray J S 2015 Impact sensitivity and the maximum heat of detonation J. Mol. Model. 211
37. Badgujar D, Talawar M, Asthana S and Mahulikar P 2008 Advances in science and technology of modern energetic materials: An overview J. Hazard. Mater 151289

38. Kosar B and Albayrak C 2011 Spectroscopic investigations and quantum chemical computational study of (E)-4-methoxy-2-[(p-tolylimino) methyl] phenol Spectrochimica Acta. A 78160

39. Klapötke T M and Witkowski T G 2015 Nitrogen-Rich Energetic 1, 2, 5-Oxadiazole-Tetrazole-Based Energetic Materials Propellants Explos. Pyrotech. 40366

40. Zamani $\mathrm{M}$ and Keshavarz $\mathrm{M} \mathrm{H} 2015$ New $\mathrm{NHNO}_{2}$ substituted borazine-based energetic materials with high detonation performance Comp. Mater. Sci. 97295

41. Guo Y-Y, Chi W-J, Li Z-S and Li Q-S 2015 Molecular design of $\mathrm{N}-\mathrm{NO}_{2}$ substituted cycloalkanes derivatives $\mathrm{C}_{\mathrm{m}}\left(\mathrm{N}-\mathrm{NO}_{2}\right)_{\mathrm{m}}$ for energetic materials with high detonation performance and low impact sensitivity $R S C A d v$. 538048

42. Keshavarz M H and Keshavarz Z 2016 Relation between Electric Spark Sensitivity and Impact Sensitivity of Nitroaromatic Energetic Compounds Z. Anorg. Allg. Chem. 642335

43. Keshavarz M H 2013 A new general correlation for predicting impact sensitivity of energetic compounds Propellants Explos. Pyrotech. 38754

44. Politzer P and Murray J S 1996 Relationships between dissociation energies and electrostatic potentials of C$\mathrm{NO}_{2}$ bonds: Applications to impact sensitivities J. Mol. Strut. 376419

45. Chi W-J, Li L-L, Li B-T and Wu H-S 2012 Density functional calculations for a high energy density compound of formula $\mathrm{C}_{6} \mathrm{H}_{6-\mathrm{n}}\left(\mathrm{NO}_{2}\right)_{\mathrm{n}}$ J. Mol. Model. 183695 